\title{
Complementary Feeding Practices and it's Associated Factors Among Mothers in Selected Urban Area of Nepal
}

Ulak $\mathrm{N}^{1}, \mathrm{KC} \mathrm{D}^{2^{*}}$, Tiwari $\mathrm{K}^{3}$

${ }^{1}$ College of Applied Food and Dairy Technology, Kathmandu, Nepal

${ }^{2}$ Nutrition Research, Nepal Health Research Council, Nepal

${ }^{3}$ Director Planning and Research, College of Applied Food and Dairy Technology, Kathmandu, Nepal

Corresponding Author: Dirghayu K.C.

Address: Nutrition Research , Nepal Health Research Council, Nepal; E-mail: dirghayu.kco1@gmail.com

Received date: 15 October 2019; Accepted date: 26 November 2019; Published date: 02 January 2020

Citation: Ulak N, KC D, Tiwari K. Complementary Feeding Practices and it's Associated Factors Among Mothers in Selected Urban Area of Nepal. Asp Biomed Clin Case Rep. 2020 Jan 2;3(1):6-14.

Copyright (C) 2020 Ulak N, KC D, Tiwari K. This is an open-access article distributed under the Creative Commons Attribution License, which permits unrestricted use, distribution, and reproduction in any medium provided the original work is properly cited.

\section{Abstract}

Poor complementary feeding contributes to the characteristic negative growth trends leading to death as well. Therefore, the present study aimed to assess complementary feeding practices and associated factors in the selected urban area of Nepal.

A community-based cross-sectional study was conducted among 237 mothers having children aged 6-23 months in Bhaktapur Municipality. Pretested structured questionnaire was used to collect data using a face-toface interview. Data were entered in Excel followed by using Statistical Package for Social Sciences (SPSS) version 20. Multinomial logistic regression was conducted to determine the feeding practices of infants as per WHO recommendation.

Out of the 237 children, $54.8 \%$ were boys and $42.2 \%$ were girls. In this study $61 \%$ were breastfed within 1 hour of birth, 33\% were given pre-lacteal feeding, 19\% were given complementary feed on time, $55 \cdot 3 \%$ had good minimum meal frequency, and $47.70 \%$ were given minimum number of food groups and $26.5 \%$ were practicing good minimum acceptable diet. Total Kcal intake supplied is equal to WHO recommended standard however, triggering $84 \%$ of participants included processed food as a part of complementary feeding which is never the good practice.

The majority of mothers lack the knowledge regarding ideal feeding practices as calorie intake was equal to WHO recommendation. There was a gap in knowledge and practice regarding duration of exclusive breastfeeding and initiation and continuation of ideal complementary feeding. The rate of complementary feeding was found on declining trend. Emphasis given to educate mothers about complementary feeding practices can be very useful for the purpose.

\section{Keywords}

Breastfed; Complementary Feeding; Kcal; Nutritional status; Processed Food 


\section{Introduction}

WHO and UNICEF define complementary feeding as the process of starting solid, semi-solid or other food to the child along with breastfeeding when breast milk alone is no longer sufficient to meet the nutritional requirements of infants [1]. Nutrition is important before, during and after pregnancy and is the most influential non-genetic factor in fetal development. Women with preconception healthy Body Mass Index (BMI) tend to gain an appropriate amount of weight during pregnancy and women with BMI below 19.1 have fivefold increased in delivering low birth weight baby. Maternal undernutrition is a risk factor for fetal growth restriction and adverse prenatal outcomes $[2,3]$.

Any non-breast milk, foods or nutritive liquids that are fed to young children after six months of age are defined as complementary foods. It is the transition of baby food from exclusive breastfeeding to family foods, with gradually increasing the amount of food from 6 to 24 months [4]. In the past, such foods were often called 'weaning foods' however, the term 'complementary food is preferred because weaning implies the cessation of breastfeeding, whereas complementary meaning to complement the breast milk along with the continuation of breast milk [5]. A proper complementary feeding consists of foods that are rich in energy and in micronutrients (especially iron, zinc, calcium, vitamin $\mathrm{A}$, vitamin $\mathrm{C}$ and folates), free from contamination (pathogens, toxins or harmful chemicals), without much of salt or spices, easy to eat and easily accepted by the infant, in an appropriate amount, easy to prepare from family foods, and at a cost that is acceptable by most families [6]. Complementary feeding is extremely essential and typically covers the period from 6 to $18-24$ months of age. WHO recommends introducing complementary feeding only from the seventh month onwards [7] because, at this age, breast milk alone is no longer sufficient to maintain the child's recommended daily allowances of nutritional requirements to enhance growth. Children are fed small quantities of solid and semi-solid foods while continuing to breastfeed up to age 2 or beyond. The amount of food is increased gradually from 6 to 23 months, which is the period of transition to eating the regular family diet. This period is characterized by an increase in the prevalence of malnutrition because of poor feeding practices and infections [8]. Feeding practices not meeting the need and requirements of children increases the risk of becoming undernourished and other health consequences even leading to death $[3,9,10]$.

Malnutrition has been responsible directly or indirectly, for $60 \%$ of the 10.9 million deaths annually among children under five. Well over two-thirds of these deaths, which are often associated with inappropriate feeding practices, occur during the first year of life. Not more than $35 \%$ of infants worldwide are exclusively breastfed during the first four months of life: Complementary feeding (too early or too late) along with poor feeding practices are often nutritionally inadequate and unsafe resulting in impaired development and becoming a major threat to socio and economic development [3,11].

The introduction of complementary feeding is a very common cultural practice in south region including Nepal which has a very high burden of malnutrition. The on-feeding practice, Nepal demographic health survey (NDHS) 2006 reported about $70 \%$ of children aged $6-8$ months children were introduced to complementary foods in Nepal [12]. Similarly, the prevalence of minimum meal frequency, minimum dietary diversity, and minimum acceptable diet were 82, 34.2 and 32\% respectively [12]. By 2011, children of 6-23 months of age were offered minimum meal frequency, minimum dietary diversity, and minimum acceptable diet was 76.6, 30.4 and 26.5\% respectively showing deteriorating conditions on feeding practices [13]. These data suggest muchneeded focus on improvement and monitoring of these practices while the interventions are being implemented in Nepal [14]. The National Demographic Health survey 2011 concluded that complementary foods are not introduced in timely fashion for all children in Nepal. 70\% of infants have been given complementary foods by age 6-9 months. Though $87.3 \%$ of mothers had knowledge about the time of initiation of complementary feed within 3 months of age and $8.9 \%$ of mothers didn't start complementary feeding even at 6 months of age. 
Both practices are not only under desirable but also harmful to our children but unfortunately, are being still practiced in the developing world [13]. Only 57\% of the mothers initiated complementary feeding at the age of 6 months. While the proportion of young children receiving minimum meal frequency was reasonably high i.e. $84 \%$ followed by meal diversity $35 \%$ and minimum acceptable diet 33\% respectively. Maternal education and with their children's growth monitored were independently associated with receiving minimum acceptable diet [15].

The introduction and use of appropriate complementary feeding are key in determining the healthy development and growth of infants. The early introduction of solids as alternatives to breast milk points that the infants are more likely to be exposed to microbial contaminated foods and fluids; which is especially the case in developing countries resulting malnourishment and/or poor growth experience. A study has also found that young infants under six months of age are not yet ready physiologically to receive complementary food as their neurodevelopment, gastrointestinal systems, and kidneys are still underdeveloped. A systematic review in 2013 found evidence suggesting that the very early introduction of solid foods (at or before an infant reaches 4 months of age), instead of at 4-6 months or $>6$ months, may result in an increased risk of infants becoming overweight in childhood [16].

The link between malnutrition and infant feeding has been well established. Infant and young child nutrition has been engaging the attention of scientists and planners since long for the very simple reason that growth rate in the life of human beings is maximum during the first year of life and infant feeding practices comprising of both the breastfeeding as well as complementary feeding (CF) have major role in determining the nutritional status of the child [17]. Infant and young children should be fed a minimum acceptable diet to ensure appropriate growth and development. Without adequate diversity and meal frequency, infants and young children are vulnerable to undernutrition, especially stunting and micronutrient deficiencies, and to increased morbidity and mortality. The WHO minimum acceptable diet recommendation, which combines minimum dietary diversity and minimum meal frequency, differs between breastfed and nonbreastfed children [7].

Nutrition plays an important role in the health and development of individuals. Adequate nutrition during the first two years of life is very important to ensure optimal physical and mental development. At this stage, children are particularly vulnerable to growth retardation, micronutrient decencies and common childhood illness such as diarrhea and acute respiratory infection. Good nutrition protects young children and mothers, strengthens the immune system and reduces the risk of non-communicable diseases related to foods during the lifecycle. It also enhances the productivity of the population and can help to get out gradually from vicious cycle of poverty and hunger. Regarding the magnitude of the issue this research hence aimed to find out situation of complementary feeding practices and the factors associated with complementary feeding practice in selected urban areas of Nepal.

\section{Materials and Methods}

A cross-sectional analytical study with face to face interview was performed starting from $16^{\text {th }}$ December 2017 to $9^{\text {th }}$ of March, 2018. 237 mothers having babies below two years of age were randomly selected as the study population from Bhaktapur district as it had very low prevalence rate of exclusive breastfeeding. The prevalence of exclusively breastfeeding at 1, 3 and 6 months were $240(74 \%), 78(24 \%)$ and $29(9 \%)$ [18]. The sample size was calculated using following relation:

$$
\text { Sample size }\left(\mathrm{n}_{\mathrm{o}}\right)=\mathrm{Z}^{2 \times} \mathrm{pq} / \mathrm{d}^{2}
$$

Where,

$\mathrm{Z}=$ (standard value of 1.96 for $95 \%$ confidence level)

$\mathrm{P}=0.83$ (prevalence rate of complementary feeding practice $83 \%$ NDHS 2016)

$\mathrm{q}=1-\mathrm{p}$

$\mathrm{d}=4 \%$ i.e. 0.04 (margin error)

Now,

$\mathrm{n}_{\mathrm{o}}=(1.96)^{2} \times 0.83 \times(1-0.83) /(0.04)^{2}$

Sample size $=210$ 
Making provision of $8 \%$ unforeseen factors the sample size was 237

\section{Data Analysis}

Data were collected by semi-structured questionnaire and face to face interview method to assess complementary feeding practice of mothers. Total Kcal of child as per WHO recommendation was then calculated. Data were entered into excel and transferred to the statistical package for the social sciences (SPSS 20) for analysis. Similarly, the categorical independent minimum meal frequency, minimum dietary diversity, minimum acceptable diet, active feeding practices, and hygiene were determined by using multinomial logistic regression. Crude odds ratio and their 95\% confidence interval (CI) were reported. Through the 24 hours recall, daily intake of food, variety of food was calculated manually based on principles and guidelines made by the Tribhuvan University Teaching Hospital (TUTH), Maharajgunj. Similarly, data were entered in Excel followed by using Statistical Package for Social Sciences (SPSS) version 20. One sample t-test was conducted to determine the Total kilocalorie (Kcal) intake of children. In addition, Multinomial logistic regression was conducted to determine feeding practices of infants as per WHO recommendation. Furthermore, all probability values less than 0.05 $(\mathrm{p}<0.05)$ have been considered statistically significant [19].

\section{Results}

Fig-1 illustrates the initiation of complementary feeding reflecting a worst-case scenario for the city

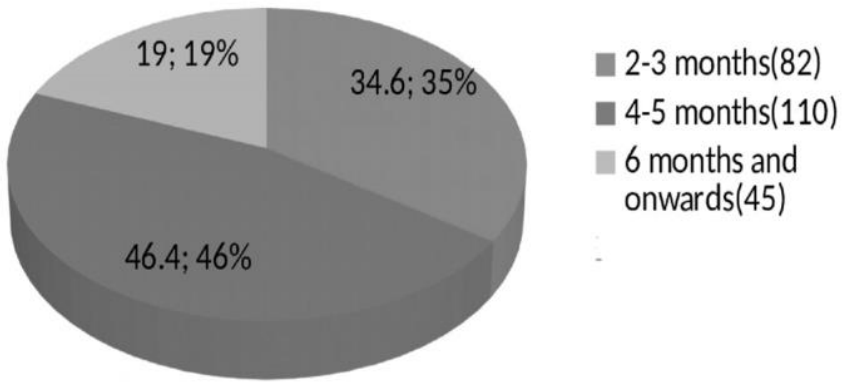

Fig-1:

Illustrates the initiation of complementary feeding practices reflecting that only small portion (19\%) introduced timely complementary feeding whereas on the downside massive $81 \%$ failed to do so.

like Bhaktapur whereby, only small portion i.e. $19 \%$ of mothers initiated complementary feeding at right time. Conversely, $35 \%$ of mothers initiated complementary feeding way before child could even develop their digestive system to digest such food. Even largest portion i.e. $46 \%$ of mothers initiated complementary feeding when their child becomes $4-5$ months of age.

Fig-2 compares the result of minimum meal frequency, minimum dietary diversity along with minimum acceptable diet of NDHS 2011, 2017 and the present study. Minimum meal frequency was seen much better in NDHS; 2011 in comparison to the least of present study. On the contrary, minimum dietary diversity in NDHS; 2011 was found low but is higher and even in both the other studies [13]. Similarly, NDHS; 2017 showed highest minimum acceptable diet [14] whereas other two are near about similar.

Table-1 shows the result from complementary feeding practices on the basis of food groups whereby it was found that all the participants agreed on including cereals and roots as a part of their complementary feeding practice followed by $91.98 \%$, $90.91 \%, \quad 78.05 \%, 30.37 \%, 36 \%$ including dairy 
Citation: Ulak N, KC D, Tiwari K. Complementary Feeding Practices and it's Associated Factors Among Mothers in Selected Urban Area of Nepal. Asp Biomed Clin Case Rep. 2020 Jan 2;3(1):6-14.



Fig-2:

Comparisons between NDHS 2011, NDHS 2017 and Column 1 (Present study) illustrating some gap in NDHS; 2011, 2017 and present study.

products, legumes, eggs, Vitamin-A rich part of their complementary feeding practice. On fruits/vegetables, and meat respectively. Conversely, further analysis is based on results from Table-1, on the downside huge portion i.e. $84.38 \%$ of Table-2 compares it with WHO (AFATVAH) in participants agreed on including processed food as relation to complementary feeding practices; food-

\begin{tabular}{|c|c|c|}
\hline \multicolumn{3}{|c|}{ Table-1: Complementary foods consumed from food groups } \\
\hline Food Groups & Frequency $(n=237)$ & Percent (\%) \\
\hline \multicolumn{3}{|c|}{ Cereals and roots } \\
\hline Yes & 237 & 100 \\
\hline No & - & - \\
\hline \multicolumn{3}{|l|}{ Legumes } \\
\hline Yes & 215 & 90.19 \\
\hline No & 22 & 9.2 \\
\hline \multicolumn{3}{|c|}{ Vitamin A rich fruits and vegetables } \\
\hline Yes & 87 & 36.22 \\
\hline No & 150 & 63.29 \\
\hline \multicolumn{3}{|c|}{ Meat and poultry items } \\
\hline Yes & 72 & 30.37 \\
\hline No & 165 & 69.62 \\
\hline \multicolumn{3}{|l|}{ Eggs } \\
\hline Yes & 185 & 78.05 \\
\hline No & 52 & 21.94 \\
\hline \multicolumn{3}{|c|}{ Dairy Products } \\
\hline Yes & 218 & 91.98 \\
\hline No & 19 & 8.01 \\
\hline \multicolumn{3}{|c|}{ Processed foods } \\
\hline Yes & 200 & 84.38 \\
\hline No & 37 & 15.61 \\
\hline
\end{tabular}


Citation: Ulak N, KC D, Tiwari K. Complementary Feeding Practices and it's Associated Factors Among Mothers in Selected Urban Area of Nepal. Asp Biomed Clin Case Rep. 2020 Jan 2;3(1):6-14.

Table-2: Child feeding practices as per WHO (AFATVAH)

\begin{tabular}{|c|c|c|c|}
\hline \multicolumn{4}{|c|}{ Table-2: Child feeding practices as per WHO (AFATVAH) } \\
\hline Characteristics & Frequency $(n=237)$ & Percent (\%) & p-value \\
\hline \multicolumn{4}{|c|}{ Knowledge of complementary feeding practice } \\
\hline Yes & 234 & 98.7 & $\mathrm{O}$ \\
\hline No & 3 & 1.3 & \\
\hline \multicolumn{4}{|c|}{ Food Frequency of the baby (F) } \\
\hline Appropriate & 214 & 91.3 & $\mathrm{o}$ \\
\hline Inappropriate & 23 & 9.7 & \\
\hline \multicolumn{4}{|c|}{ Amount of food intake (A) } \\
\hline Appropriate & 194 & 81.9 & \\
\hline Inappropriate & 43 & 18.1 & 0.229 \\
\hline \multicolumn{4}{|c|}{ Thickness of food (T) } \\
\hline Appropriate & 220 & 92.8 & \\
\hline Inappropriate & 17 & 7.2 & 0.734 \\
\hline \multicolumn{4}{|c|}{ Variety of food (V) } \\
\hline Appropriate & 113 & 47.7 & \\
\hline Inappropriate & 124 & 52.3 & 3.514 \\
\hline \multicolumn{4}{|c|}{ Active feeding while eating (A) } \\
\hline Yes & 96 & 40.5 & \\
\hline No & 141 & $59 \cdot 5$ & 4.012 \\
\hline \multicolumn{4}{|c|}{ Hygiene of child (H) } \\
\hline Yes & 217 & 91.6 & \\
\hline No & 20 & 8.4 & 0.115 \\
\hline
\end{tabular}

\begin{tabular}{|l|r|r|r|}
\hline \multicolumn{4}{|c|}{ Table-3: Comparison of this study and WHO recommendation on total kilocalorie intake } \\
\hline \multicolumn{1}{|c|}{ Characteristics } & Frequency(n=237) & Mean \pm SD & P-value \\
\hline 6-9 months & 73 & $278.49 \pm 146.72$ & $<0.001$ \\
\hline 9-12 months & 70 & $467.86 \pm 164.23$ & $<0.001$ \\
\hline $12-24$ months & 94 & $540.11 \pm 204.66$ & 0.064 \\
\hline
\end{tabular}

frequency of the baby, amount, variety, active feeding and hygiene of child results from this study was found significantly associated. According to WHO, amount of complementary calorie requirement differs according to age groups of infant start at six months of age Infants age with small amounts of food for age group 6-9, there is significant difference in mean calorie intake by that age group6-9 and age group 912 , there is significant difference in mean calorie intake by that age group than the calorie set intake by $\mathrm{WHO}$ as $\mathrm{p}$-value $=<0.01$ which is less than significance level 0.05. While for age group 12-24, there is no significant difference in mean calorie intake than the required calorie recommended by WHO as p-value o.640. The study showed that as the age of child advanced calorie intake reduced. Also, the energy needs from foods for infants with "average" breast milk intake are approximately $200 \mathrm{Kcal}$ per day at 6-8 months of age. Table-3 showed that the age group from 6-9 months children meets the Kcal intake as per WHO with overall mean Kcal intake of 278.49 \pm 146.72 . Similarly, the energy needs from complementary foods for infants with "average" breast milk intake are approximately 300 Kcal per day at 9-12 months. This data of study shows that the age group from 9-12 months children meets the Kcal intake as per WHO guidelines with overall mean kcal intake $467.86 \pm 164.23$. Likewise, the energy needs from complementary foods for infants with "average" breast milk intake are approximately 550 Kcal per day 
at 13-23 months. This study shows that the age group from 12-24 months children meets the Kcal intake as per WHO guidelines with overall mean kcal intake $540.11 \pm 204.66$.

\section{Discussion}

Results reflected the worst-case scenario in the city like Bhaktapur, for introducing complementary feeding, only small portion were able to introduce complementary feeding on time whereby large portion failed to do so which, mainly is because of the gap between knowledge and practice, level of awareness and somewhat influenced by cultural and social norms as well. Even more surprising is the percentage i.e. $84 \%$ of participants including processed food as a part of their complementary feeding practices.

Similar to this study, minimum meal frequency is a proxy for a child's energy requirements. For infants and young Breastfed children are considered to be consuming minimum meal frequency depending on the food they receive i.e. solid, semisolid, or soft foods, at least twice a day for infants 6-8 months, only $83 \%$ of children age $6-8$ months received timely complementary foods [20]. Among 237 children age 6-23 months, less than half (47.67\%) were given foods from four or more food groups in 24 hours during study period while only $47 \%$ were given foods from four or more food groups in the 24 hours preceding the survey of 2016 NDHS, 18\% in 2011 NDHS and $37 \%$ in 2014 NMICS. This shows a lot of differences in feeding practices among mothers from 2011 study till now. Children from disadvantaged group, children who have less than five-member in the house, children whose mothers age was more than 20 years at their first childbirth, children of fathers and mothers who were literate and children who were non-continuously breastfed till date of study were likely to receive foods from four or more groups than those children from advantage group, children who have family members more than five in the house, Children whose mothers age was less than 20 years at their first childbirth, children of mothers and fathers with no education and children who were having continuous breastfeeding. A study conducted in a peri-urban community of Dhaka, Bangladesh and the Advanced Biomedical Research ward (ABRU) showed that maximum intake of complementary food from single meal for any combination of dietary energy density and feeding frequency ranged from $16.5-37.09 / \mathrm{kg}$ body weight (mean25.0 \pm 6.0 ) for the different children [21].

World Health Organization (WHO) presented that more than $30 \%$ of children under the age of 5 years suffer from developmental growth, of which $80 \%$ suffer from reduced height growth rate, $20 \%$ are underweight. The inadequacy of proper nutrition during pregnancy is indicative of intrauterine growth restriction affecting brain development. Low maternal weight before conception is associated with an increased risk of low birth weight and symmetrical growth restriction and pregnancy loss. In developing countries, intrauterine growth restrictions are mainly due to poor maternal nutrition and infections, which makes up to $11 \%$ of births. Furthermore, low birth weights babies are more likely to be stunted by the age of two years. The prevalence of developmental disorders in developing countries is higher than in other parts of the world. In most of these countries, the children's physical growth and infants are lower than international standards. To address the gap of between knowledge and practice World Health Organization (WHO) and United Nations Children's Fund (UNICEF) emphasized exclusive breastfeeding (EBF) for six months, i.e. 180 days and addition of complementary foods at six months of age with continued breastfeeding till the child becomes two years of age. Poor feeding practices, coupled with high rates of infectious diseases, are the proximate causes of malnutrition during the first two years of life. The second half of an infant's first year is especially a vulnerable time when breast milk alone is no longer sufficient to meet his /her nutritional requirements and CF should be started [16]. During the period of CF, the young child gradually becomes habituated to eating family foods. Complementary foods bridge the gap in terms of energy, vitamin A, and iron intake, which occurs in breastfed infants at six months of age. Too early or too late introduction of $\mathrm{CF}$ may lead to nutritional deficiencies of iron, zinc, calcium, and vitamins. Therefore, $\mathrm{CF}$ needs to be nutritionally adequate and safe and appropriately fed to meet the 
energy and nutrient needs of the young child [15]. CF is also influenced by cultural factors, beliefs, and knowledge of parents on appropriate practices. Similarly, psychosocial care, safe preparation and proper storage of complementary foods, and hygiene practice are also important determinants of proper $\mathrm{CF}$ practices. The same study showed the prevalence of timely introduction of complementary feeding among infants aged 6-8 months was $84 \%$, minimum dietary rate was $31.5 \%$, minimum meal frequency was found to be $36.7 \%$ and the rate of maximum acceptable diet was $7 \cdot 3 \%$ [22].

Breastfed children are considered to be fed within the minimum standards if they consume at least four food groups and receive food other than breast milk at least twice a day in the case of infants 6-8 months, at least three times a day in the case of children 9-12 months and at least three times meal with 2 times snacks in the case of children aged 13-23 months [23]. However, because of the small percentage of 6-8 months' infants in this study, a separate analysis for this group of infants is not done.

This study showed that of all the children, 98.7\%of breastfed children were fed the minimum number of times in the 24 hours. While in the NDHS report 2016, $71 \%$ of breastfed children were fed the minimum number of times in 24hours, and in NDHS 2011 report, $78 \%$ and in NMICS report, $74.4 \%$ received solid, semi-solid and soft foods the minimum number of times or more during the previous day.

\section{Conclusion}

Despite their satisfactory results on Total calorie intake, child feeding practices were found poor mainly because of gap between knowledge and practice, level of awareness and somewhat influenced by cultural and social norms as well.

\section{Acknowledgment}

Authors like to acknowledge Prof. Jagat Bahadur K.C., Mr. Yek Bahadur Rana, Mr. Roshan Dhaubadel, Saroj Thapa, Ms. Anju Panthee, Mr. Bicky Raut, Ms. Sukriti Ghimire, Mr. Kuber Lal Giri and Himalayan Food and Agri-Bio Research Industries for their support during the whole research period.

\section{Conflict of Interest}

The authors declare no conflict of interest.

\section{References}

[1] World Health Organization. Complementary Feeding: Summary of Guiding Principles. Report of the Global Consultation, 10-13 December 2001. Geneva, Switzerland: World Health Organization; 2002.

[2] Campbell RK, Aguayo VM, Kang Y, Dzed L, Joshi V, Waid J, Gupta SD, Haselow N, West KP Jr. Infant and young child feeding practices and nutritional status in Bhutan. Matern Child Nutr. 2018 Jul;14(3):e1258o. [PMID: 29266829]

[3] Mutua MK. Patterns and determinants of breastfeeding and complementary feeding practices in urban informal settlements, Nairobi Kenya. 2017.

[4] Dewey KG, Brown KH. Update on technical issues concerning complementary feeding of young children in developing countries and implications for intervention programs. Food Nutr Bull. 2003 Mar;24(1):5-28. [PMID: 12664525]

[5] Black RE, Allen LH, Bhutta ZA, Caulfield LE, de Onis M, Ezzati M, Mathers C, Rivera J; Maternal and Child Undernutrition Study Group. Maternal and child undernutrition: global and regional exposures and health consequences. Lancet. 2008 Jan 19;371(96o8):243-6o. [PMID: 18207566]

[6] Adhikari M, Khanal V, Karkee R, Gavidia T. Factors associated with early initiation of breastfeeding among Nepalese mothers: further analysis of Nepal Demographic and Health Survey, 2011. Int Breastfeed J. 2014 Dec 5;9(1):21. [PMID: 25493094]

[7] World Health Organization. Guiding principles for feeding non-breastfed children 6-24 months of age. 2005 .

[8] Cumming LS. International Baby Food Action Network (IBFAN). International Encyclopedia of Civil Society. 2010:880-1.

[9] Dewey KG. The challenge of meeting nutrient needs of infants and young children during the period of complementary feeding: an evolutionary perspective. Nutr. 2013 Dec;143(12):2050-54. [PMID: 24132575]

[10] Muchina EN, Waithaka PM. Relationship between 
breastfeeding practices and nutritional status of children aged o-24 months in Nairobi, Kenya. African Journal of Food, Agriculture, Nutrition and Development. 2010;10(4).

[11] Zlotkin SH, Christofides AL, Hyder SM, Schauer CS, Tondeur MC, Sharieff W. Controlling iron deficiency anemia through the use of home-fortified complementary foods. Indian J Pediatr. 2004 Nov;71(11):1015-19. [PMID: 15572823]

[12] Joshi N, Agho KE, Dibley MJ, Senarath U, Tiwari

K. Determinants of inappropriate complementary feeding practices in young children in Nepal: secondary data analysis of Demographic and Health Survey 2006. Matern Child Nutr. 2012 Jan;8 Suppl 1:45-59. [PMID: 22168518]

[13] Khanal V, Sauer K, Zhao Y. Determinants of complementary feeding practices among Nepalese children aged 6-23 months: findings from Demographic and Health Survey 2011. BMC Pediatr. 2013 Aug 28;13:131. [PMID: 23981670]

[14] Pandey S, Tiwari K, Senarath U, Agho KE, Dibley MJ, South Asia Infant Feeding Research Network (SAIFRN)*. Determinants of infant and young child feeding practices in Nepal: secondary data analysis of Demographic and Health Survey 2006. Food and nutrition bulletin. 2010 Jun;31(2):334-51.

[15] Saleh F, Ara F, Hoque MA, Alam MS. Complementary feeding practices among mothers in selected slums of Dhaka city: a descriptive study. J Health Popul Nutr. 2014 Mar;32(1):89-96. [PMID: 24847597]

[16] World Health Organization. Infant and young child feeding: model chapter for textbooks for medical students and allied health professionals. 2009 .

[17] Profile IN. Department of Women and Child Development. Ministry of Human Resource Development, Government of India, Government of India Press, New Delhi. 1998:216-26.

[18] Ulak M, Chandyo RK, Mellander L, Shrestha PS, Strand TA. Infant feeding practices in Bhaktapur, Nepal: a cross-sectional, health facility based survey. Int Breastfeed J. 2012 Jan 10;7(1):1. [PMID: 22230510] [19] Acharya S. Legal Measures of Nepalese Financial System: An Overview. Available at SSRN 3389607. 2019 May 17.

[20] Lamichhane R, Zhao Y, Paudel S, Adewuyi EO. Factors associated with infant mortality in Nepal: a comparative analysis of Nepal demographic and health surveys (NDHS) 2006 and 2011. BMC Public Health. 2017 Jan 10;17(1):53. [PMID: 28068969]

[21] Islam MM, Ahmed T, Peerson JM, Mollah MAH, Khatun M, Dewey KG, et al. Energy density and feeding frequency of complementary foods affects meal-specific food consumption and meal duration by healthy, breast fed Bangladeshi children. Adv Pediat Res. 2016;3:1-11.

[22] American Physiological Society; World Medical Association General Assembly. Guiding principles for research involving animals and human beings. Am J Physiol Cell Physiol. 2002 Jun;282(6):3. [PMID: 12035793]

[23] Subedi N, Paudel S, Rana T, Poudyal AK. Infant and young child feeding practices in Chepang communities. J Nepal Health Res Counc. 2012 May;10(21):141-46. [PMID: 23034377] 